\title{
Gummatous lesions in men infected with Human Immunodeficiency Virus and Syphilis
}

\author{
P E Hay, F W K Tam, V S Kitchen, S Horner, J Bridger, J Weber
}

\begin{abstract}
Two HIV-infected men are reported who developed gummatous lesions more than 12 months after appropriate treatment of presumptive syphilis. In one patient the lesions developed without any change in the VDRL titre. The most likely explanation for these lesions is reactivation of syphilis in the context of HIV infection. As these lesions respond to penicillin, the possible reactivation of appropriately treated syphilis, or even yaws, should now be considered in any ulcerative lesion in HIV infected individuals at risk from treponemal infection.
\end{abstract}

\section{Introduction}

The ulcerative or nodular manifestation of benign tertiary syphilis known as a gumma occurred in $16 \%$ of 1147 patients with untreated syphilis in the Oslo Study. ${ }^{1}$ It is now rarely seen although a decline in incidence was noted prior to the introduction of penicillin. ${ }^{2}$ A gumma is thought to represent an enhanced immune response to Treponema pallidum as organisms are present in low numbers in the lesions. Healing occurs promptly after antimicrobial treatment leaving a "tissue paper" scar.

Many HIV-positive patients have a history of syphilis, and it has been suggested that the natural history of syphilis is altered in such patients with an increased probability of treatment failure, and an

Clinical Research Centre, Watford Road, Harrow, Middlesex HA1 3UJ

P E Hay

Infectious Diseases Unit, Hammersmith Hospital, Du Cane Road, London W12 0HS

F W K Tam, J Weber

Department of Genito-Urinary Medicine, St Mary: Hospital, Norfolk Place, London W2 1NY

P E Hay, V S Kitchen

Department of Pathology, St Mary's Hospital, Norfolk Place, London W2 1NY S Horner

Department of Pathology, Hammersmith Hospital, Du Cane Road, London W12 0HS, UK

J Bridger accelerated progression to manifestations of tertiary neurosyphilis. ${ }^{3-6}$ In the last 2 years two cases of benign tertiary syphilis in HIV-positive men have been reported from London, and one in an HIV antibody negative homosexual man. ${ }^{78} \mathrm{We}$ report a further two cases in HIV-positive men.

\section{Case 1}

A 44 year old bisexual man presented in 1985 with a painless ulcerated lesion on the penis (fig 1a). He had a long history of treatment for syphilis, which is summarised in fig 2. He was born in Jamaica, and received a course of bismuth in Antwerp one year prior to his first course of procaine penicillin in the UK in 1967 . He had many sexual partners over the next 15 years, and was treated for gonorrhoea on four occasions. He had multiple courses of treatment for syphilis. On three occasions small dark-ground negative genital lesions developed in association with a rise in VDRL titre.

In the mid 1970s bilateral sensorineural hearing loss developed in association with interstitial keratitis. Despite prolonged courses of steroids and penicillin almost total deafness ensued over the next 5 years. The occurrence of these two features of Hutchinson's triad suggested the diagnosis of congenital infection, although they can occur in acquired infection. Mild aortic regurgitation was diagnosed in 1976. Whilst this may have been unrelated to syphilis, cardiovascular involvement is more likely to occur in late acquired than in congenital syphilis. It is possible that he had manifestations of both. The last treatment for syphilis was in 1984, following contact with an infectious individual, when he received epidemiological treatment with doxycycline $300 \mathrm{mg}$ per day for 10 days. The VDRL titre remained at $1 / 64$ before and after this treatment. During the intervening year he had reduced his number of partners to two, after being advised that he was a hepatitis B carrier.

The ulcer had been steadily increasing in size until it measured $6 \mathrm{~cm}$ by $3 \mathrm{~cm}$. Generalised lymphadenopathy was noted. Serum antibodies to HIV 1 were present, and the VDRL titre was now $1 / 512$. Repeated dark-ground examinations were negative. A biopsy was performed to exclude malignancy. The histological features were consistent with benign tertiary syphilis, showing granulomatous inflamma- 

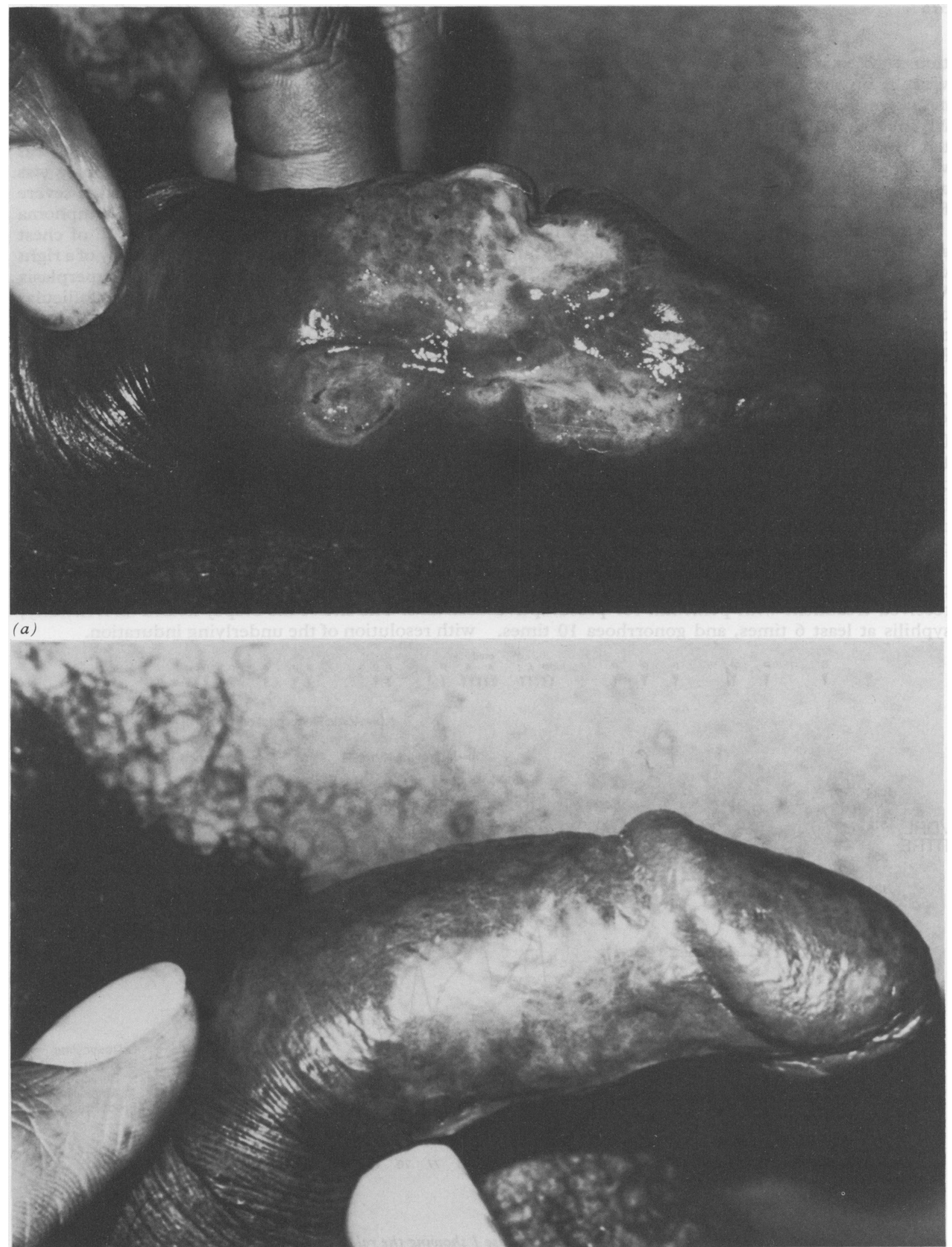

(b)

Figure 1 (a) A large painless penile ulcer in case 1, prior to treatment. (b) Healed ulcer in case 1, six weeks after treatment with penicillin. There is scarring on the underside of the penis, corresponding to the site of the gumma. 
tion with sparse giant cells. There was marked vascular involvement with adventitial cuffs of plasma cells admixed with chronic inflammatory cells (fig 3 ). Mycobacteria, fungi and treponemes were not detected by appropriate stains or electron microscopy. It was concluded that the lesion was a gumma, and absence of necrosis was due to the biopsy being taken from the edge of the lesion.

Benzathine penicillin (2.4 MU) was administered and repeated after 6 days. The ulcer healed within 6 weeks, with some residual scarring (fig 1b). The VDRL titre fell to $1 / 32$. Further courses of doxycycline have not produced any change in the VDRL titre. The lymphadenopathy remains the only sign of HIV infection.

\section{Case 2}

A 51 year old bisexual man, originating from Dominica, was diagnosed HIV antibody positive in 1987 when he presented with peri-anal ulceration due to Herpes simplex, generalised non-tender lymphadenopathy, and oral candidosis. He had tissue paper scars on his legs compatible with his history of previously treated yaws.

His sexual history included frequent visits to prostitutes. Over the previous 25 years he had received treatment with penicillin for presumptive syphilis at least 6 times, and gonorrhoea 10 times.
Tetracycline had been administered for non-gonococcal urethritis on nine occasions. Serological tests for syphilis showed a positive RPR on undiluted serum, TPHA and FTA both strongly positive.

Treatment with acyclovir and ketoconazole was commenced, and zidovudine $200 \mathrm{mg} 4$ hourly was added in 1988. At that time he complained of severe generalised pruritis. The possibility of lymphoma was considered, but chest radiograph, CT of chest and abdomen were normal. Excision biopsy of a right inguinal lymph node showed follicular hyperplasia with plasma cell proliferation in the interfollicular areas, but no evidence of lymphoma.

In 1989 two nodular lesions, $0.5 \mathrm{~cm}$ in diameter, developed in his right groin. There was induration with superficial ulceration (fig 4). Syphilis serology was unchanged from 1987. Histological examination of an excision biopsy showed the features of a gumma. Treponemes were not seen on silver stains, and no fungi or mycobacteria were visualised, or grown on culture.

There was no evidence of neurological or cardiovascular syphilis. Chest radiograph, cardiac ultrasound, bone scan and cerebrospinal fluid examination were normal. A course of three doses of 2.4 MU benzathine penicillin was administered over 3 weeks. The site of the biopsy healed uneventfully, with resolution of the underlying induration.

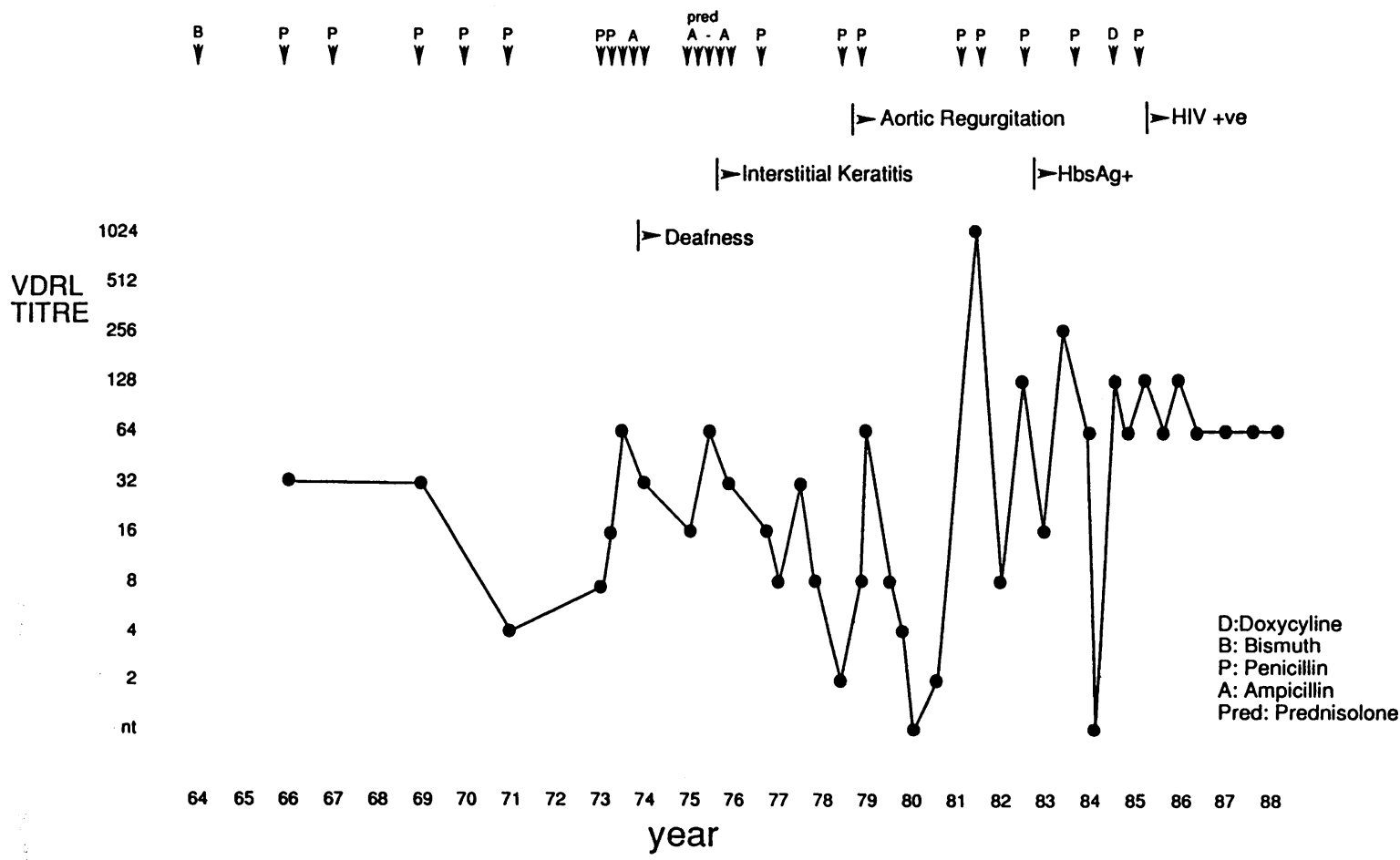

Figure 2 Outline of 19 years of syphilis and treatment in case 1 showing the relationship between serum VDRL, time, development of complications and courses of treatment for syphilis. 


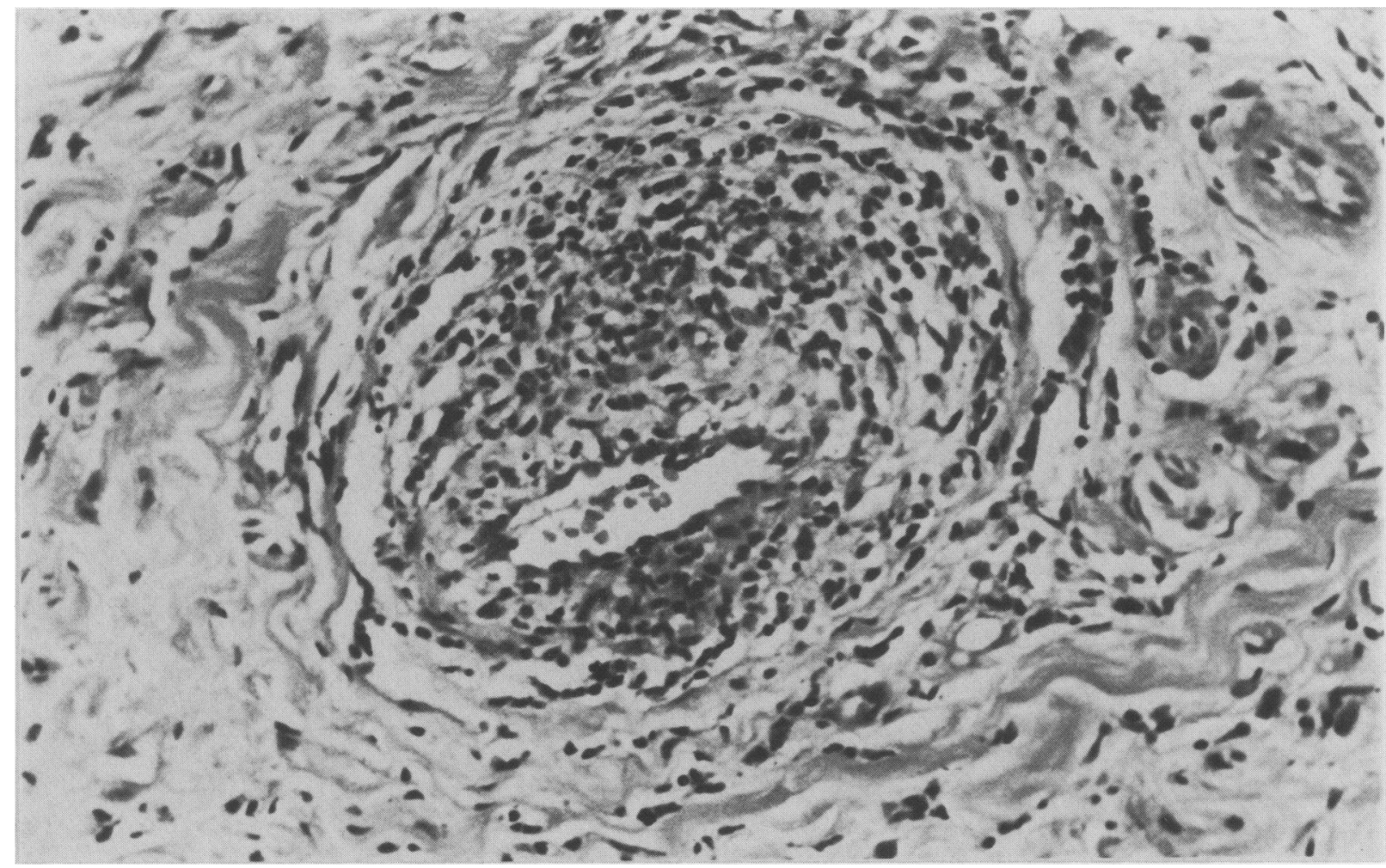

Figure 3 Histological section from penile biopsy in case 1 showing periarteritis in a sub-dermal arteriole, with adventitial cuffs of plasma cells and lymphocytes, admixed with chronic inflammatory cells (Haematoxylin and eosin $\times 190$ ).

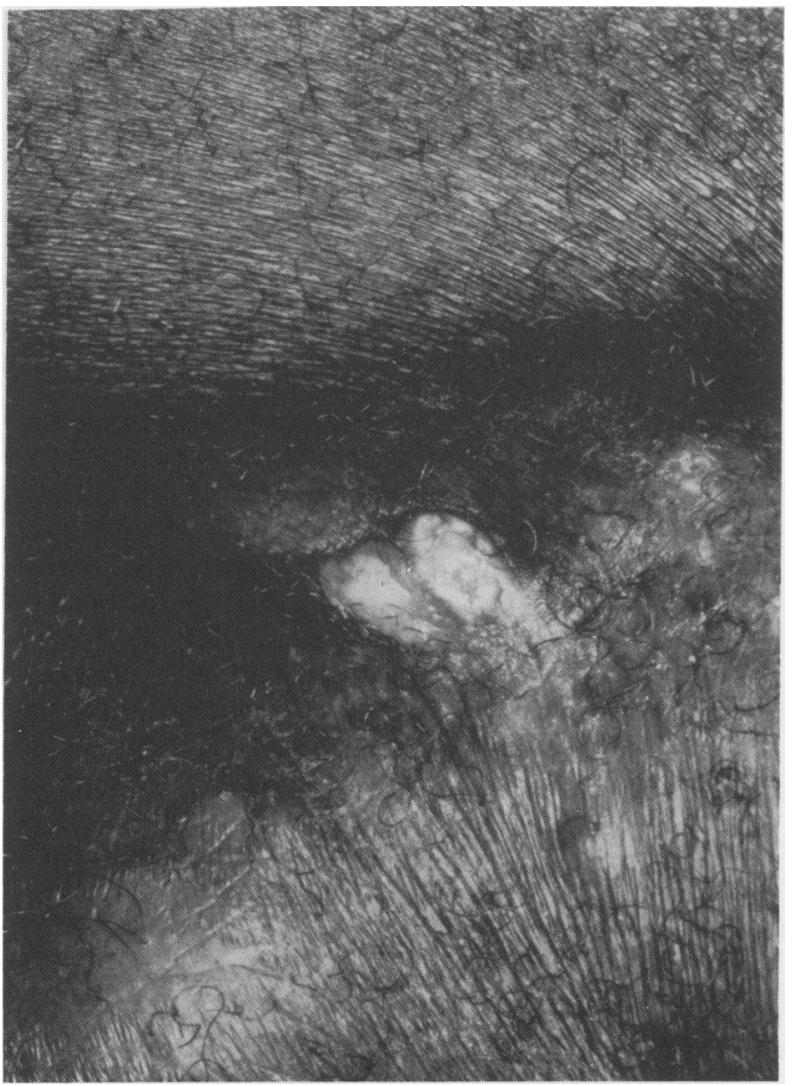

Discussion

Histologically a gumma is a granuloma with epithelioid and giant cells present, obliterative endarteritis and areas of necrosis. It is thought to represent a hypersensitivity response to a small number of treponemes. Olansky extensively reviewed the aetiology of gummas and concluded that they can arise either from reactivation of syphilis present in an untreated or inadequately treated individual, or from reinfection in a previously sensitised individual. ${ }^{9}$ Certainly gummas can follow reinoculation in sensitised individuals. In the SingSing Prison study, in which Nichols strain $T$. pallidum was inoculated into human volunteers, one of the five subjects with a history of treated congenital syphilis developed a gumma at the site of inoculation, as did one of the patients with previously treated late syphilis. ${ }^{10}$ The term pseudo-chancre redux has been applied to gummatous lesions occurring at the site of an earlier chancre. ${ }^{11}$ It is distinguished from a chancre redux by the absence of demonstrable treponemes on a dark ground examination and of local lymphadenopathy. Although the patient described in case 1 never had a chancre demonstrated in our clinic it is possible that this was a pseudo-chancre redux.

There is evidence that $T$. pallidum persists in some patients who have received what is regarded as adequate therapy for syphilis. ${ }^{12-16}$ It has been suggested that $T$. pallidum persists in a state of commenFigure 4 Ulcerated lesions in the groin of patient 2. sality, with the potential to recover its virulence 


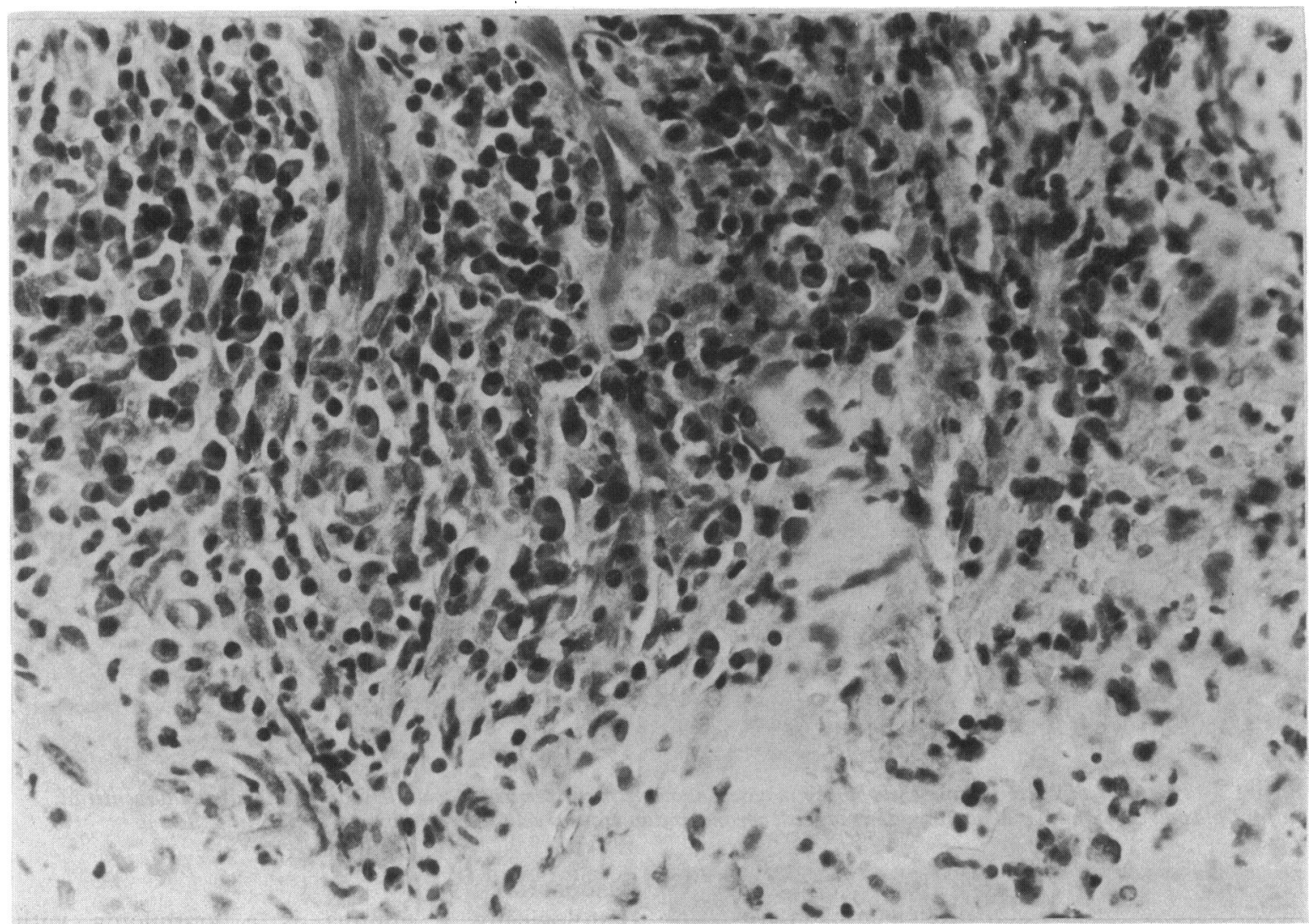

Figure 5 Histological section from biopsy of case 2. There is acanthosis and hyperkeratosis, with vascular proliferation in the underlying dermis. The blood vessels are cuffed with large numbers of plasma cells. Small areas of necrosis are present amongst the cellular infiltrate (Haematoxylin and eosin $\times 190)$.

under appropriate conditions, ${ }^{17}$ and that a combination of adequate antimicrobial therapy and normal immune function is required to prevent reemergence of disease. ${ }^{6}$ In experimental rabbit syphilis steroid induced immunosuppresion is associated with an increased number of organisms in the primary lesion, with delay in development of the humoral and cellular immune response and in elimination of the organism. If cortisone is administered whilst the lesion is healing, effector activity is diminished with impaired macrophage function and the reappearance of treponemes. ${ }^{18}$ In a proportion of rabbits previously infected with syphilis and treated with penicillin, administration of cortisone led to the appearance of skin lesions of tertiary syphilis. ${ }^{15}$ Passive transfer of serum from rabbits with immunity to syphilis results in modified susceptibility to infection in the recipients with an increased incubation period and a decrease in the severity of infection. ${ }^{19}$ IgG in such serum interferes with the ability of treponemes to attach to cells and disseminate. However, cell-mediated immunity probably plays the major role in suppression of infection..$^{20}$ In healing primary lesions macrophages contain partially degraded and whole treponemes whilst infiltration by specifically sensitised $T$ lymphocytes is associated with the clearance of treponemes. ${ }^{2122}$

Patients at risk from reactivation of $T$. pallidum infection would appear to be those with iatrogenic immunosuppression and those with concurrent HIV infection, producing alteration in immune function. Syphilis presenting in an atypical manner with hepatitis and periostitis as predominant presenting features has been reported in transplant recipients. ${ }^{2324} \mathrm{~A}$ case of neurosyphilis has been described in a homosexual man found to be HIV seropositive after a renal transplant. ${ }^{25}$ Recommended treatment for primary syphilis had been given 3 years earlier, and reinfection was considered unlikely. In St. Mary's Hospital approximately $48 \%$ of HIVpositive patients have a history of syphilis (365/761 patients seen between 1985 and 1988 for whom data were available, unpublished observation, $\mathrm{PEH})$. The 
two cases of gummas in HIV seropositive men which we describe here and the two previously reported by Dawson et al, ${ }^{7}$ occurred in patients without AIDS. If gummas arise at increased frequency in HIV-positive subjects it presumably reflects a subtle alteration in the cellular immune response to $T$. pallidum.

As the precise nature of the immune regulation of latent treponemal infection is unknown we can only speculate as to how it is modified by concurrent HIV infection.'The most likely explanation is that the loss of $\mathrm{CD}^{+}$cells or $\mathrm{CD}^{+}$macrophage dysfunction allows the emergence of a small number of treponemes and a subsequent brisk hypersensitivity reaction. It has been reported that type 1 hypersensitivity may paradoxically be exacerbated as patients progress to AIDS. ${ }^{26}$ In the two cases reported here the initial source of the treponemes was presumed to be old infection, there being no history to suggest reinfection in either case. In one case there was no rise in VDRL titre to assist in diagnosis. Treatment for syphitis led to resolution of the lesions in both patients. The past history of yaws in the second case suggests the possibility that either $T$. pallidum or even $T$. pertenue may become reactivated by concurrent HIV infection.

Address for correspondence: Dr P E Hay, The Jefferiss Wing, St Mary's Hospital, Praed St, London W2 1NY, UK.

1 Gjestland T. The Oslo study of untreated syphilis: an epidemiologic investigation of the natural course of syphilitic infection based on a restudy of the Boeck-Bruusgaard material. Acta Derm Venereol 1955;35(supplement 34): 3-368.

2 Kampmeier RH. Late benign syphilis. In: Holmes KK, Mardh PA, Sparling PF, Wiener PJ, eds. Sexually Transmitted Diseases, First edition. New York: McGraw Hill Inc, 1984.

3 Johns DR, Tierney M, Felsenstein D. Alteration in the natural history of neurosyphilis by concurrent infection with the human immunodeficiency virus. $N$ Engl $J$ Med 1987; 316:1569-72.

4 Tramont EC. Syphilis in the AIDS era. $N$ Engl $J$ Med 1987;316:1600-1.

5 Berry CD, Hooton TM, Collier AL, Lukehart SA. Neurologic relapse after benzathine penicillin therapy for secondary syphilis in a patient with HIV infection. $N$ Engl J Med 1987;316:1587-9.
6 Lukehart SA, Hook EW, Baker-Zander SA, Collier AL, Critchlow $C W$, Handsfield $H H$. Invasion of the central nervous system by Treponema pallidum: implications for diagnosis and treatment. Ann Int Med 1988;109:855-62.

7 Dawson S, Evans BA, Lawrence AG. Benign tertiary syphilis and HIV infection. AIDS 1988;2:315-6.

8 Kitchen VS, Cook T, Doble A, Harris JRW. Gummatous penile ulceration and generalised lymphadenopathy in homosexual man: case report. Genitourin Med 1988;64:276-9.

9 Olansky S. Late benign syphilis (gumma). Med Clin North Am 1964;48:653-65.

10 Magnusson HJ, Thomas EW, Olansky S, Kaplan BI, De Mello $\mathrm{L}$, Cutler JC. Inoculation syphilis in human volunteers. Medicine (Baltimore) 1956;35:33-82.

11 Langan-O'Keefe PM. Pseudo-chancre redux. Br Med J 1965; ii:212.

12 Dunlop EMC. Survival of treponemes after treatment: Comments, clinical conclusions and recommendations. Genitourin Med 1985;61:293-301.

13 Rice NSC, Dunlop EMC, Jones BR, et al. Treponeme like forms in treated and untreated early syphilis. $B r J$ Venereal $D i s$ 1970;46:1-9.

14 Wiet RJ, Milko DA. Isolation of the spirochetes in the perilymph despite prior antisyphilitic therapy. Arch Otolaryngol 1975;101:104-6.

15 Collart P, Borel LJ, Durel P. Significance of spiral organisms found, after treatment, in late human and experimental syphilis. Br J Venereal Dis 1964;40:81-9.

16 Tramont EC. Persistence of Treponema pallidum following penicillin $\mathrm{G}$ therapy. JAMA 1976;236:2206-7.

17 Poitevin M, Collart P, Bolgert M. Syphilis in 1986. J Clin Neuroophthalmol 1987;7:11-16.

18 Lukehart SA, Baker-Zander SA, Lloyd RMC, Sell S. Effect of cortisone administration on host-parasite relationships in early experimental syphilis. J Immunol 1981;127:1361-8.

19 Fitzgerald TJ. Pathogenesis and immunology of Treponema pallidum. Ann Rev Microbiol 1981;35:29-54.

20 Pavia CS, Folds JD, Baseman JB. Cell-mediated immunity during syphilis. $\mathrm{Br} J$ Venereal Dis 1978;54:44-150.

21 Lukehart SA, Baker-Zander SA, Lloyd RMC, Sell S. Characterisation of lymphocyte responsiveness in early experimental syphilis. J Immunol 1980;124:461-7.

22 Ovcinnikov NM, Delektorskij VV. Current concepts of the morphology and biology of Treponema pallidum based on electron microscopy. Br J Venereal Dis 1971;47:315-8.

23 Johnson PC, Norris SJ, Miller GPG, et al. Early syphilitic hepatitis after renal transplantation. $J$ Infect Dis 1988;58: 236-8.

24 Peterson LR, Mead RH, Perlroth MG. Unusual manifestations of secondary syphilis occurring after orthotopic liver transplantation. Am J Med 1983;75:166-70.

25 Clark R, Carlise JT. Neurosyphilis and HIV infection. South Med J 1988;81:1204-5.

26 Parkin JM, Eales L-J, Galazka AR, Pinching AJ. Atopic manifestations in the acquire immune deficiency syndrome: response to recombinant interferon gamma. $\mathrm{Br} \mathrm{Med} J 1987$ 294:1185-8.

Accepted for publication 5 July 1990 